\title{
From mourning to environmentalism: a Sicilian controversy about children's deaths, political apathy and leukemia
}

\author{
Gaetano Mangiameli ${ }^{1}$ \\ University of Bologna, Italy
}

\section{Introduction}

Political apathy is harmful to health. This sentence summarizes the voices of activists concerned about a leukemia cluster and deaths from the disease in Lentini, Sicily, who have been calling for explanations for more than two decades. Their campaign calls into question a division between 'natural' and 'social' explanations for disease. The case is an example of the contrast between common sense, folk wisdom, and public opinion on the one hand, and bureaucracy and the state on the other.

Since the late 1980s, the town of Lentini has experienced growing concern about the incidence of leukemia among children. In order to shed light on this phenomenon, a campaign was launched by a civic association that unified people whose children had died of leukemia. As a reaction to an embarrassed silence by government institutions about a possible leukemia cluster, campaigners kept on demanding official explanations.

This article describes the construction of the aetiology of leukemia and its cultural aspects, and underlines how asymmetries of power structure the cultural frames of interpretation of the disease. I ask, how was leukemia constructed as a social object in this case? What kind of social capital and what kind of cultural capital were used in order to frame the disease? The bottom-up discourse of campaigners framed leukemia as an environmental disease connected to wider socio-political phenomena affecting Sicily and Italy. They adopted a cultural filter that selected extraordinary, outrageous, and sensationalist circumstances as acceptable explanations, insofar as children's deaths were also considered extraordinary. The most frequently mentioned factor underlying the incidence of the disease was the management of radioactive waste, which is allegedly related to the US Naval Air Station located nearby at Sigonella and/or to the dumping of radioactive waste in the countryside by the Mafia.

\section{Methodology and 'facts'}

Questions about the social production of toxic uncertainty are often related to a 'solid ground' which is taken as a matter of fact and upon which different opinions emerge. For an example, the sociologists Auyero and Swinston (2008) start from the following questions: "How do people perceive an environmentally risky situation? When do they fail to understand what is objectively a clear and present danger?" (Auyero and Swinston 2008: 357). The underlying assumption is that there is a common ground of reality upon which different actors construct different meanings, namely their opinions. This very assumption cannot be taken for granted in the case presented in this article. At the present moment a comprehensive and shared account of the facts claimed by anti-leukemia activists is not available. On the one hand, local citizens, either in public or in private, show a high degree of awareness about the factors underlying leukemia, or - to be more explicit - a deep confidence in the worst case scenario (namely the involvement of an American air base in Sicily called Sigonella, or the Mafia); on the other hand, their suspicions have not yet been legitimated by public authorities. While popular rumours and journalistic inquiries have been feeding a bottom-up narrative which connects several presumed facts in a web of suspicions, there is no top-down counter-narrative coming from the State. Furthermore, the bottom-up narrative and the top-down silence are related, since the attitude of formal institutions has stimulated the worst suspicions.

In this case, the factual ground is somewhat slippery. In such context, as an anthropologist, I do not aim at providing a full account of factual reality, through a journalistic account or a data-based historical reconstruction. My purpose, here, is the elicitation of the cultural instruments that have been used to attribute meaning to children's death.

The article is based on my prolonged experience on the field as an ethnographer who is also a native citizen of Lentini (Figure 1). In other words, I have constructed an intimate knowledge of the context over a long period of time, as I was growing up in the town. As a consequence, my research belongs to the category of endogenous ethnography or endo-ethnography (Van Ginkel 1998). Over (at least) fifteen years I have witnessed numerous conversations about leukemia in Lentini. Furthermore, I have read a number of brief and

\footnotetext{
${ }^{1}$ Dr. Gaetano Mangiameli, Postdoctoral Fellow and Temporary Lecturer, DiDiSAG - Dipartimento di Storia Culture Civiltà, University of Bologna, Italy. Email: gaetano.mangiameli "at" unibo.it. Thank you to two anonymous reviewers and the editors. This paper is in Koensler A. and C. Papa (eds.) "After anthropocentrism? Environmental conflicts, social movements and power," special section of the Journal of Political Ecology 20: 255-341.
} 
frustrating references to the relation between environmental pollution and childrens' deaths in local newspapers, websites and social media. All these sources point to the same catalogue of facts.

Insofar as the Mafia is allegedly involved in this affair, and some issues currently covered by State secrecy, the matter needs to be handled with care. In order to respect ethical and methodological principles, then, I will provide a summary of the main aspects of the story without attributing the account to any specific supporter of the campaign who discussed the issue in public or private. Furthermore, since from a legal point of view the Italian Republic has never acknowledged - or replied to - any of the attempts to clarify this matter, I rely on the contents of a Parliamentary question that three Senators addressed to three Ministers of the Italian Government in 2007. This information has also come up in everyday conversations, and in a case presented in 2006 by Manuela \& Michele - Associazione per bambini leucemici ('Association for leukemic children', hereafter referred to as MM) at the Procura della Repubblica of Siracusa (the Siracusa District Court).

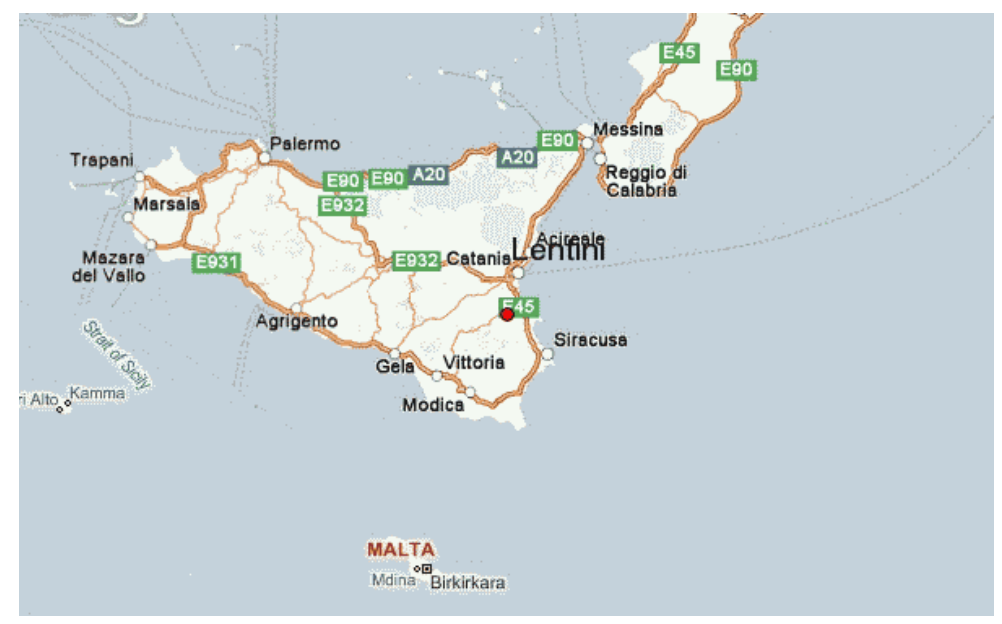

Figure 1: Lentini, Sicily. The Lago di Lentini is 3km north-west, and the Sigonella U.S. Naval Air Station is $17 \mathrm{~km}$ north of the town.

In this document, the Associazione MM presented evidence that radioactive waste from public hospitals in Northeastern Italy might have been illegally transported and discharged around Lentini and that a further significant amount of radioactive material might have been locally released due to a US military plane crash, described below. The 2006 court case has yet to reach a resolution. Indeed, the fact that the case is still ongoing - officially, at least - is considered in positive terms by the activists, as they fear the inquiry itself could have simply disappeared without trace.

The 2007 parliamentary question was proposed by three Senators. Liotta, Russo Spena and Martone from the PRC (Partito della Rifondazione Comunista) were elected to the Italian Senate in 2006. They asked the Minister of Environment, the Minister of Health and the Minister of Defense for a detailed scientific inquiry about leukemia in Lentini, Carlentini and Francofonte, given local concerns and mortality in these places. The three senators cited reportage in the media, and a report on cancer published by the local Health Authority (ASL 8 - Siracusa) as their sources, in order to bring the case to the Government's attention. They raised four points;

- First, the leukemia mortality rate in the area is the "highest in Italy and it is still increasing", with special reference to children's death.

- Secondly, the Health Authority report suggests the hypothesis that the leukemia cluster might be related to nuclear pollution.

- Thirdly, the town of Lentini, whose territory hosts the NATO base of Sigonella dominated by US forces, is also very close to the area where two accidents currently covered by State Secrets occurred in 1984 and 1985, involving US Air Naval Force units. The 1984 accident is the most frequently mentioned in the social discourse on leukemia. ${ }^{2}$ When on 12 July 1984 a US military aircraft carrying depleted uranium as ballast crashed in the countryside close to

\footnotetext{
${ }^{2}$ See for example http://invisibil.blogspot.it/2007/09/leucemie-e-radiazioni-lentini.html
} 
Lentini, ${ }^{3}$ the area was secured by the Americans just 12 minutes after the accident and then was kept under their control for four months, during which time the Italian authorities were not allowed in.

- Fourthly, the DIA (Direzione Investigativa Antimafia) has discovered that the Sigonella Base used to discharge its waste in illegal dumps managed by companies whose owners were actually proxies for the Santapaola-Ercolano Mafia family.

The Senators asked whether the Minister of Health and the Minister of Environment were willing to launch an inquiry in order to clarify the relation between children's death and radioactive pollution, and, secondly, whether the Minister of Defense was willing to remove the State Secret classification currently covering any information related to the air crashes occurred close to Lentini. As it is possible to see on the website of the Italian Senate, the parliamentary question was accompanied by a formal request for written reply. After six years, the Government has not yet answered, and the three Senators' question is currently filed as 'on course. ${ }^{4}$

Besides the widespread suspicions pointing at the military base, the involvement of Mafia in local discourses about leukemia is not surprising, as crimes against the environment are becoming part of their core business. The use of the Italian neologism ecomafia, coined by Legambiente (League for the Environment), the biggest Italian environmentalist association, is now common. ${ }^{5}$ Legambiente labels any criminal organization that carries out illegal activities affecting the environment (in its broadest sense) as ecomafia: illegal dumping and construction, trafficking in exotic animals, illegal excavations, and theft of archaeological heritage.

\section{Folk statistics: environmental justice and the right to know}

To develop the understanding of the Lentini case, I will explain the major features of the anti-leukemia campaign, and how the leukemia cluster came to public attention. A group of families in Lentini whose children had died of leukemia formed MM (Manuela \& Michele - Associazione per bambini leucemici) in 1990. Manuela and Michele were the first two victims. Since the beginning, the work of MM has been twofold: on the one hand, MM aimed at obtaining a reliable account of the phenomenon; on the other hand, they supported people affected by leukemia and their families. ${ }^{6}$

MM activists were probably more effective with the second task, not only by attending the funerals of leukemia victims and offering moral support to the bereaved, but also by providing financial support to those who were coping with the disease, and their fundraising commitment was quite successful. By approaching the relatives of those who had suffered from the disease, MM did not just pursue the task of supporting them. If the moral and financial support to families was a way to alleviate their pain, it was also an attempt to get them involved as new members: for MM, the quest for the truth about the local epidemiology of leukemia was the only conclusive solution.

With regard to the second point, namely how the leukemia cluster became a culturally shaped public issue, it must be underlined that the core of the campaign consists of a question mark. Even though from the outset MM pushed for an explanation based on environmental factors connected to radioactive pollution (political or cultural) rather than genetic factors ('natural'), the Lentini anti-leukemia campaign is not a localized movement driven by a NIMBY (Not In My Back Yard) reaction. Rather than saying "not in my back yard", from the outset, the activists have been asking "what's in my backyard?" even though (and paradoxically) they claim to know the answer.

The right to know, I argue, is fundamental to any possible enactment of environmental justice, along with the right to interact with the natural environment. In fact, before any specific issue can be evaluated, before any content, opinion or decision is shared, discussed or taken, environmental justice and environmental rights must be based on knowledge, and that knowledge can be based either on official and external sources or on direct interactions between human beings and their environment. According to the British anthropologist Tim Ingold, there is an;

\footnotetext{
${ }^{3}$ Reported here http://aviation-safety.net/database/record.php?id=19840712-0

${ }^{4}$ See

http://banchedati.camera.it/sindacatoispettivo_15/showXhtml.Asp?idAtto=15903\&stile=6\&highLight=1\&paroleContenut $\underline{\mathrm{e}}=$

$\overline{5}$ The Ecomafia report has been published by Legambiente on annual basis since 1997. See http://www.legambiente.it/contenuti/progetti-e-azioni/rapporto-ecomafia

${ }^{6}$ http://www.manuela-michele.it
} 
...alleged discrepancy between what, in modern jargon, are called 'local' and 'global' perspectives. Insofar as the latter, afforded to a being outside the world, is seen to be both real and total, the former, afforded to beings-in-the-world (that is, ordinary people) is regarded as illusory and incomplete. (Ingold 2000: 211)

It seems that before they exercise the right to decide what is permitted in their environment, people can claim the right to know what has been happening and what is going on here and now - this is precisely what the anti-leukemia activists declare. Having said this, the local perspective is relevant to this case in two respects.

First, as environmental injustice has to do with people who "have less ability to control the environmental insults imposed on them" (Shrader-Frechette 2002: 3), the right to know can be rethought as a right to interact, a right to be engaged with one's own surroundings, and then redefined as right to know/interact-with the environment. In other words, controlling one's own environment is encapsulated in a direct, personal, prolonged interaction with the environment which is the best guarantee of people getting to know it, to identify it and then to protect it in order to protect themselves. Needless to say, this is getting more and more difficult for people living in urban areas surrounded by a countryside that often becomes the perfect location for illegal or non-declared activities, or sometimes for legal activities the consequences of which are unknown or not clear, precisely because the authorities are unable or unwilling to address them. When people do not directly control their environment (either because they cannot or because they renounce the task), they lose a fundamental aspect of their humanity. And this too is a matter of rights: claimed, denied, contested, forgotten rights. This case suggests the idea that environmental justice must be based on the right to know/interact-with the environment.

Secondly, local perspectives assume (without fully acknowledging it) the asymmetry of power that separates them from the detached form of knowledge that is peculiar to scientific reasoning. In the case of the Sicilian anti-leukemia campaign, the local perspective needs the hard statements of science in order to be validated, but, at the same time, the latter is expected to provide precisely the response that the former has already made available. The neutrality of science is a chimera.

In this context, the anti-leukemia campaign is also a struggle to induce social institutions to become reflexive. According to Michael Fischer, reflexive social institutions are;

...responses to decision-making requirements when unprecedented ethical dilemmas arise. Examples include (...) environmental and ecological arenas, where toxic threats to ground water, plant life, and human health require citizen action panels with their own (limited) ability to hire independent experts to negotiate with (less limited) corporate, military or government expertise and authority. (Fischer 2007: 540)

In fact, MM have indeed tried to draw upon the opinion of independent experts, but these were not taken into account by the authorities.

When MM began its activities, there were no local statistics on the incidence of leukemia. Epidemiological data now show that the incidence is higher in Lentini than the Italian national average. But it is necessary to distinguish between statistics, and local perception. The data were made available quite late, after lobbying from the MM campaign. The campaign began from the individual experiences of people whose children had died of leukemia rather than from analysis of mortality statistics. In other words, before obtaining a reliable explanation of the incidence of leukemia, it was necessary to assess the reality. This task was not easy to achieve, as the process by which individual perceptions struggle to reach the level of public relevance is complex and controversial. While statistical data, whether or not based on accurate scientific standards, provide a knowledge that is supposed to be objective, the local perception of the phenomenon has a strong moral dimension and perhaps a lower level of credibility.

The campaign had its starting point when a few people (the founders of $\mathrm{MM}$ ) realized that two children belonging to the same narrow horizon of personal relations had died of leukemia. The informative source of the campaign consisted of 'folk statistics', which are generally based on what happens in the immediate relational surroundings of the observer. In other words, folk statistics were sourced from local perspectives. The bereaved households launched a campaign whose main aim was, and still is, transforming the multiple views of a matter of concern into the illusory unity of a non-problematic matter of fact. That is, obtaining from a top-down scientific point of view what was already clear to the organisation, in order to force the political sphere to act. After struggling to obtain an official register of cancer-related deaths, MM have kept on contesting the reliability of the figures: according to them, in fact, many fatalities were simply recorded as 'cardiac arrest' without mentioning leukemia. The anti-leukemia campaign is a struggle for local perspectives to turn into a global ones, or, in other words, for morally-oriented folk statistics to obtain the acknowledgment of their reliability that is peculiar to science. 


\section{Appealing to science}

Before introducing a brief survey of scientific views on leukemia and discussing the field of socially constructed explanations for the incidence of the disease in Eastern Sicily, it is important to deal with a conceptual impasse over the use of the adjective 'natural.' Despite an alleged infringement of the 'natural flow of life', the anti-leukemia campaign has an ambivalent attitude towards the concept of 'nature' in the sense that it is sometimes used by unsophisticated environmentalists, namely as a neutral and balanced order that is objectively knowable. The separation of 'humanity' and 'nature' in two different 'houses' is at the core of Latour's definition of the "Constitution of modernity". In the first are;

...the totality of speaking humans, who find themselves with no power at all save that of being ignorant in common, or of agreeing by convention to create fictions devoid of any external reality...

while the second one is the domain of non-humans;

...real objects that have the property to define what exists but that lack the gift of speech (Latour 2004: 14).

As non-humans 'contain' indisputable truths but cannot communicate them, the interpretation of their message is entrusted to science, which is seen as neutral and objective.

The strategy commonly adopted by environmental activists is to appeal to the objectivity of science in order to enlighten environmental threats to human health. Such a strategy could be an example of the typical error that Bruno Latour denounces (Latour 2004). Too many times, he argues, the denunciation of the environmental effects of modernity is based on concepts that reintroduce that very fallacy of modernity that is at the core of the issue: the separation between 'nature' - non-human objects whose rules of behaviour can be observed and described by science - and society, a world of subjects living in the chaos of opinions and contradictions. ${ }^{7}$ Sometimes the frame of environmental campaigns is based on the idea that a mysterious and unspecified 'natural balance' might have been disturbed by human actions, although activist claims are not always related to 'nature' in such a naïve manner as Latour believes them to be. What really deserves more attention is the nature of the appeal to science. Here, Latour seems to be right: science is enlisted as an arbiter of truth, deemed more powerful than multiple opinions.

With regard to leukemia, unfortunately, science finds it difficult to meet the need for certainty. It is useful to take into account a brief review of different statements made by scientists in recent articles about leukemia in different areas of the world. For an example, a team of scientists "...concluded that there was an over-all association between childhood leukemia and maternal prenatal occupational pesticide exposure" (Wigle, Turner and Krewski 2009: 1511), whereas another scientific publication "...corroborates earlier findings on the association between paint exposure at home and ALL (Acute Lymphoblastic Leukemia) risk in childhood" (Scélo et al. 2009: 139). Furthermore, one source notes "...the potentially greater susceptibility of older workers to benzene-induced leukemia" (Richardson 2008: 374), while another "...observed an increasing risk of ALL associated with increasing residential concentrations of PCBs (polychlorinated biphenyls)" (Ward et al. 2009: 1013), which are considered "...probable human carcinogens and cause perturbations of the immune system" (ibid). Ward and his team "...found no evidence of a relationship between ALL risk and exposure to DDT (dichlorodiphenyltrichloroethane), DDE, chlordane or pentachlorophenol" (ibid).

In addition, as Belson et al. state;

...epidemiologic studies of acute leukemias in children have examined a number of possible risk factors (e.g., environmental, genetic, or infectious) in an effort to determine the aetiology of the disease. Only one environmental risk factor (ionizing radiation) has been significantly linked with either ALL or AML (acute myeloid leukemia); most environmental risk factors [e.g., electro-magnetic fields (EMFs), cigarette smoking] have been weakly or inconsistently associated with either form of childhood leukemia. (Belson, Kingsley, and Holmes 2007: 138)

On the contrary, cigarette smoking is considered relevant by Kasim et al. (2005) with regard to adult leukemia: "This study confirms the link between active smoking and adult AML, and adds some evidence that obesity increases the risk of different types of adult leukemia. Our study also suggests a possible protective role of obesity against the risk of AML associated with active smoking" (Kasim et al. 2005: 499). The last

\footnotetext{
${ }^{7}$ See also the introduction to this Special Section (Koensler and Papa 2013).
} 
statement seems to underline that leukemia is able to jumble up imageries and expectations about the boundary between healthy and unhealthy choices and behaviors. Obesity, which in the contemporary context is considered unhealthy, could be a positive factor in preventing leukemia. Uncertainty about the interpretation of leukemia is the keyword also for Pang et al. (2002), who argue that "some Asian migrant groups retain one or more factors that partially protect them against development of leukemia. Whether these factors are primarily genetic, lifestyle or environmental, or a mixture, remains to be determined" (Pang et al. 2002: 795).

To sum up, despite the fact that "...elevated rates of leukemia among populations in the vicinity of nuclear establishments have been found repeatedly" (Schmitz-Feuerhake et al. 1997: 1502), generalisations about leukemia are still not tenable. In this empty space, conversely, there is room for culturally-driven suspicion. Furthermore, once it is acknowledged that the quest for a single causal explanation is a chimera, and that, consequently, the incidence of leukemia should be understood in terms of multifactorial models, no one can make any kind of straightforward statement that science is still supposed to make. In other words, although scientists do not aim at providing simple, deterministic accounts of reality, it seems that they are still expected to provide precisely this.

It is interesting to notice how the anti-leukemia campaign, which demands scientific explanations and simultaneously constructs its own account, mixes the first Latourian house and the second one, effectively merging the intrinsic social character of ecology as an intertwining of humans and non-humans: 'environmental' definitely means 'social', not 'natural'. Basically, as ecosystems are social systems too, ecology becomes a matter of associations. Consequently, the 'ecological' is intrinsically social. Indeed, aiming at using a better terminology to understand the roots of the phenomenon, we can use 'humans' as a substitute for 'social' and 'non-humans' as a substitute for 'ecological.' Nonetheless, separating humans and non-humans (namely society and nature) is a dead-end street, since it is hard to find any ecological (non-human) chain of events in which humans have not played a role, or any social (human) actions that lack non-human mediation. This is the main reason why I fully appreciate Bruno Latour's view, as expressed in his Reassembling the social: by quoting the work of Gabriel Tarde, he reminds us that the social is not "...a special domain of reality but a principle of connections" (Latour 2005: 13). Tracing associations is precisely what social actors do as they live, think and work in an environment. Tracing associations, as it will be shown in the next section, means building relations between people in order to act together, and connecting different phenomena in order to understand them. In the case of leukemia in Eastern Sicily, even though people seem to be looking for a panacea, in other words for solutions meant as 'content' that might explain and solve their problems, what they really need is 'relations', or connections and associations (Koensler and Papa 2013). As local people apparently fail to cooperate, complaining about political apathy is part of the self-diagnosis stimulated by leukemia in the community.

\section{Structural suspicions: when society needs to be reassembled}

More than two decades after launching their campaign, the anti-leukemia activists are still trying to make the political and health institutions acknowledge the eco-social roots of leukemia. Nevertheless, there is actually no debate, as the activists' question remains unanswered. Furthermore, the very label 'eco-social' is poorly specified. Which eco-social factor is key? What kind of assemblage of humans and non-humans should people blame? Since many explanations are possible, and the institutions prefer avoiding knee jerk reactions, the negotiation between them and the activists is unlikely to arrive at 'The Truth', but will elicit one possible shared explanation that may sound acceptable. Even though the activists describe themselves as common citizens lacking the scientific competence necessary to produce a credible account about leukemia, they have their own preferences about how a credible account might look, as explained in Section 2.

Because of a sort of conceptual short circuit, unnatural deaths in Sicily needed to be connected to 'environmental' factors. This involves a re-reading of the notion of environment itself, not as a synonym for nature. The label 'environmental factors' is increasingly elided with 'cultural or social factors.' In recent years, the social discourse on leukemia has created a complex scenario for the understanding of this phenomenon, providing multiple explanations that are connected to how people use or modify their environment. On the contrary, in a public meeting on leukemia at the Lentini City Council Hall, the head of the District Health Agency refused to endorse the social discourse on radioactive pollution and proposed to focus on genetic factors (see below). But if children's deaths are unnatural, then an explanation based on genetic factors is absolutely unsatisfactory, as it would remove human responsibility for the prevalence of the disease.

While waiting for public authorities to provide answers, the activists started tracing associations. As time went by, leukemia attracted a number of different possible interpretations, all of which are environmentrelated and could potentially bring about public scandal. According to the discourse emerging from popular rumours and journalistic inquiries, the incidence of leukemia might have been determined by a number of different factors, namely the controversial and mysterious air crash of 1984, the use of pesticides in local agriculture, the presence of nuclear materials or weapons in the NATO base of Sigonella, or the Mafia's illegal management of radioactive waste perhaps coming from hospitals in Northern Italy and even from the Sigonella military hospital. 
Among these factors, the first one is certainly the most frequently cited. Depleted uranium, pesticides, nuclear weapons, and toxic waste all became the actors of a screenplay that was written over and again. Each of the elements of this cahier de doléance formed the basis for public accusations;

- First of all, concern over toxicity and contamination;

- Secondly, a moral judgement about those who allegedly produced the contamination (the USA, local farmers, the North of Italy, the Mafia);

- Thirdly, a moral judgement about those who were supposed to prevent the contamination (political authorities);

- Lastly, probably the most important moral judgement, one blaming the local community itself for avoiding a collective action that would be a backlash against the political sphere. Again, the problem has a deeply political nature.

Having ascertained that the airplane crash is the most frequently mentioned explanation, news about other possible factors (as the ones mentioned above) seem not to contradict such conviction by the activists. The other outrageous factors that are taken into account in everyday discourses do not either replace the air crash or exclude one another. More elements for different conspiracy theories actually reinforce the circuit of suspicions and self-blaming, a process that is still active. As an example, as I was working on this article I happened to read, by chance, some words written in a polemic tone by a citizen of Lentini in his Facebook page. His post (originally written in Sicilian dialect) went as follows: "Come, come here! Come and throw your waste here! We will welcome your waste and keep tumors and deformities for us!" In this case, as in uncountable other examples, an accusation of entities located 'outside' (the State, the USA, and/or hospitals of Northern Italy) is accompanied by an accusation directed 'inwards', to local peoples' apathy, whereas the Mafia acts as communication device between the 'inside' and the 'outside', in order to make this conspiracy theory wear the cultural features of a 'typically Sicilian' story. Childrens' deaths definitely have deeply moral implications that have nothing to do with the inescapable character of 'nature.' Evil is anthropogenic and it is to be unmasked by science.

No matter what the 'official scientific explanation' of leukemia in Lentini will sound like (if it is ever provided), the discourse on leukemia has already attained the status of a moral commentary about local society and its "malcontents", to quote Jean and John Comaroff (Comaroff and Comaroff 1993). Politically active actors constructed a framework for understanding the local community itself and for identifying its social disease. What appears to be a disordered ensemble of possible causes interacting in a complex system is reduced to some simple statements about collective life in contemporary Sicily. An account about the decadence of Lentini is constructed, something that people discuss every day. The content of this diagnosis is well known: even though contamination allegedly stems from trans-local actors, such as the USA and the Mafia (just to mention the most prominent ones), the local community is to be blamed because its political apathy is the necessary precondition for trans-local actors to produce dangerous contamination. Leukemia becomes a cultural connector that helps people to draw an ordered image of local disorder.

In everyday conversations the alleged connection between the disease and other major social dysfunctions is usually given as a matter of fact. The following example can be used to illustrate this point. During the Fascist period (1922 to 1945) the marshland of Biviere (Lago di Lentini or Lago Biviere) was drained. It had been a dangerous source of malaria for the inhabitants of the nearby town of Lentini. The original project included the construction of dams to create a new lake. But the works only started several decades later, during the 1980s, and the lake was finally filled in 1990. Although the history of the lake was linked to malaria risk, once it 'came back to life' in a new form, it was deemed a new opportunity for local development, both in terms of agriculture and tourism. Yet it has never been open to the public. So far, its only use has been the provision of water for agricultural purposes. Nowadays, the inhabitants of Lentini look at the lake as a missed opportunity and this is more than an economic issue. As local people cannot have any kind of direct interaction with a major element of their environment connected to local imageries, oral traditions and written literature, they have no chance to live and experience the lake rather than seeing it merely as a non-human object.

In spite of the many complaints by local citizens, opening the lake to public access is not part of the political agenda. In my view, the absence of interaction between local people and their lake, on the one hand, and the absence of any kind of feedback between local people and the politicians who represent them, on the other, are two aspects of the same social disease, which today is also one of the most worrying features of Italy as a whole. It is worth noticing how the activity of tracing associations by the social discourse about leukemia has connected the disease to the lake. After the 1984 air crash, according to information for the most part shared in town, the Americans removed a huge amount of soil from the area and took it elsewhere. This unknown 'elsewhere' is identified by local people as being in the dams of the new artificial lake, which were built in the same period. As no answer was ever obtained about the environmental consequences of the air crash by any political institution, at local, regional or national level, the absence of feedback appears to be 
structurally similar to the absence of feedback about the management of the lake. Consequently it was culturally consistent among local people to trace a line that associated the air crash, leukemia and the lake. The fact that they are not allowed to visit the lake (that is 'to interact with their environment'), the fact that locals have no control over what happens in their environment, and the fact that too many people die of leukemia, are all part of a single issue of environmental justice, referred to, first of all, as the right to know what happens in the environment.

In order to grasp the relevance of cultural connections, it is useful to bear in mind some of the stories and urban legends that are frequently told about the lake. Because of radioactive pollution, I was told, freakish fish and monster-like birds dwell in it. Accounts like these show the suspicions of those who believe them, but they are also meaningful for understanding the social discourse. These rumours, in fact, shed an anthropocentric light on the social discourse to which they belong. This focus on 'monsters' is not related to a concern towards nature as such, but as an evidence of a toxic environment that is dangerous to humans, and consequently perceived as an issue of environmental injustice.

\section{6. "We had to become environmental activists"}

The attitude of MM towards environmentalism is ambivalent, insofar as it is still in the making. During an interview in December 2010, one of the prominent members of MM made the following statement: "We had to become environmental activists." This needs some clarification. First of all, it implies that MM did not start from an environmentalist position, but that it is approaching environmentalism. Secondly, MM did not endorse the ideology of environmentalism, or any of the many versions of environmentalist ideology. In fact, MM maintains what we might label an 'anthropocentrism by default', a non-declared form of Western traditional anthropocentrism. Their motive for action is based on personal experiences of grief. They are mourners, and mourners of a special kind, as they have survived their children. Given that the death of a child, as it has already been said, is read as being 'against nature', it deserves a kind of moral explanation, which cannot be anything but political. Although the activists claim that they have purposely avoided any political affiliation, as they think that 'death is beyond politics', the choice of grief as the medium for tracing associations among a community of mourners does have political effects. The social capital that was mobilized by the anti-leukemia activists consists of personal relations of kinship and friendship, whereas cultural capital is not derived from any form of self-conscious political ideology, but from the social value of family. The strength and the weakness of MM is rooted in its social and cultural capital. On the one hand, its values were effective in directing financial support towards people affected by leukemia, and their moral support towards the bereaved. On the other hand, MM lament that as members of the association recover from their loss, they become progressively idle. Even though not all the members are people directly hit by the death of somebody, this is certainly a serious limitation for MM's ambitions.

For MM, supporting the mourners is a first step. After that, members should work with MM in order to build a shared horizon of meaning. The final goal is a reliable account about the incidence of leukemia and then, hopefully, the removal of the underlying factors, so that, perhaps, "it will never happen anymore.'

Responses to death are currently turning to the private sphere: they involve families and their network of most intimate relations (Ariès 1977; Thomas 1975). In addition, the main political feature of the local population is its low level of cooperation and the absence of feelings and actions directed towards common belonging and shared interest. In other words, as many critically-oriented inhabitants complain, the social disease of the town consists of poor political activity in the public sphere about collective issues. Once more, leukemia has socio-political roots. All the factors usually cited as underlying leukemia can keep on operating as long as there is no collective reaction. The experience of mourning, seen as a tool for tracing associations, seems to work in a self-referential way. Definitely, if taken alone, it seems to be more an obstacle than an instrument for laying the foundations of a new active citizenship, because it does not manage to break the dynamics that weaken a broad social integration. If, as Goodman writes, "poverty is a viciously biocultural cycle" (2009: xv), I would add that political poverty (poverty in terms of social capital and of means of political expression) is a vicious cycle as well. In fact, despite the politically devastating potential of the issue, the activists have been unable to connect their campaign to national or international ones, with the unfortunate consequence that their campaign is still restricted to the extremely narrow dimension of a local case.

\section{A political response for a political problem}

In March 2011, MM organized a conference in town about leukemia. The key speaker was the head of the District Health Agency, who was expected to support the activists' claims. On the contrary, his aim appeared to be of a somewhat different nature, as he was loyal to the authority he represented. As Zavetoski et al. (2004:266) showed, authorities adopt "the prudent public model in constructing a master frame that depicts the agency as sensitive to the public's knowledge and concerns, and as a trustworthy champion of environmental and public safety." In order to do that, authorities need to use a series of sub-frames supporting a master framing of an issue: these are termed the "historical-not-chronic-source" frame, the responsiveness frame, the collaboration frame, the minimization frame, the "reliance-on-science" frame, the "caution-not- 
alarm" frame and the "public-protector" frame (Zavetoski, Agnello, Mignano and Darroch 2004: 266). The head of the agency tried to reduce alarmism, improving confidence in the health agency and underlining the centrality of scientific method in contrast with the circulation of groundless rumours.

He introduced his paper by underlying that he was about to say something scientific, based on empirical evidence and accurate methodological standards. After framing his speech in this way, he spoke about the accident of 1984, he compared the actual peak levels of leukemia during the 1980s and the expected peak level of leukemia related to a possible radioactive contamination after the accident, and showed the audience that they did not fit. The head of the agency did not discuss the other politically embarrassing explanations, because of the lack of any detailed information. Even though he claimed he was unable to provide any conclusive explanation, he underlined that two factors deserved more attention, both less politically embarrassing than others. The first, in fact, is the use of pesticides in local agriculture. According to the available data about Sicily, he stated, the incidence of leukemia is higher than the national average in all the specific areas in which agriculture is the main activity. The second one is genetics. More precisely, he mentioned a factor known as population mix. He talked about the possibility that local people, in the past, did have a genetic defence from leukemia that they might have lost recently. During the 1960s and the 1970s, when the orange business was at its maximum levels, the town attracted very poor immigrants from a small town in the district of Messina. Population mix, then, could have weakened local peoples' genetic defence from leukemia.

Genetics, which is understood as 'nature', plus a 'social' factor, namely immigrants, produces an argument that nobody, among us, is guilty. Exactly as the activists have been doing, the head of the local health agency traced his own associations, even though he would have labelled them neutral scientific conclusions. It goes without saying that the activists were not satisfied with such conclusions.

What really worries the activists is the total absence of any kind of participation by politicians and the majority of fellow citizens. If, as Phelan et al. (2004) have stated, "...for causes of death about which we know little in terms of prevention and treatment, the near ubiquitous association between socioeconomic status and mortality would be strongly diminished" (Phelan et al. 2004, 278), then leukemia seems to be dramatically democratic, as its incidence is so unforeseeable that it appears to be random. It can hit anybody anywhere, despite the social status of victims. Denying or ignoring the problem allows the disease to keep on working as a sort of game of chance. Furthermore, denying or ignoring the problem cannot result from any hidden strategy of personal survival. In this case it is impossible to separate one's own health from collective health, as nobody can be effective in pursuing the first while ignoring the second. Nevertheless, the majority of the inhabitants and politicians themselves prefer avoiding any kind of direct, personal, explicit endorsement of the issue. The absence of active citizenship oriented towards a full control of the (social) environment leaves an empty space. And this is precisely the space in which leukemia grounds its roots.

\section{Conclusion}

In conclusion, the agency of local people seems to be very limited, with regard to the control they exert over their environment and over political institutions. While the social discourse was connecting leukemia to a toxic local environment and was looking for the factors underlying alleged toxicity, local campaigners were also trying to connect people together to increase the level of community involvement in the issue. The experience of failure in the attempt to get more people involved stimulated the elaboration of a moral commentary about their own society and its political apathy.

Environmental justice reveals itself to be the core of social justice and welfare in a broad sense, as the attempt to achieve an understanding of leukemia leads local campaigners towards an environmentalist position. In this case, anthropogenic threats to the environment (in the form of nuclear compounds or waste, or possibly pesticides) are the source of a discourse that connects public interest into a web of interrelated matters (Latour 2005: 87-120), each of which contributes to identifying specific aspects of ecological danger that are related to local people's insufficient power. The connection between 'toxic environments' and 'damages to human health' is mediated by a concern about democracy, meant as a condition that is to be attained and refreshed continuously through the active participation of citizens. Furthermore, far from being rooted in the global environmental movement, the anti-leukemia activism described in this article is moving, step by step, from a private form of mourning to a public commitment to environmentalism.

The State, in turn, did not to open any kind of dialogue with local people on this matter, implicitly showing the asymmetry of power between those who ask questions and those who are supposed to reply but also have enough power to refuse to do it. The cultural shape of the social discourse, with its emphasis on sensationalist explanations, definitely stems from two different factors: the exceptional nature of children's deaths, on the one hand, and the suspicious silence of the institutions, which stimulated this multi-vocal narrative. It is in this sense that the symmetries of power structured the social discourse.

The case shows that leukemia is a socio-political disease that can affect a community insofar as the latter is incapable of exerting direct control on its own environment or acting in order to restore such power. In sum, the continued abnormal incidence of leukemia stems from political apathy. The multi-vocal discourse 
on leukemia evokes practices that are conceivable only in a context in which the local community entirely devolves power to other actors or institutions, firstly to the State, and, at the same time, renouncing control over it. In this context, common references heard in the community to the Mafia as being guilty of illegal management of toxic waste are not surprising. The Mafia is the root of many Sicilian social dysfunctions and also the result of those dysfunctions. The loss of power of one's own territory and the incapability of acting politically in the public scene are two aspects of the same problem: first, there can be no environmental justice without local sovereignty; secondly, there can be no local sovereignty without political participation. In this way, toxic environments and social dysfunctions, or landscape and society, are revealed as intertwined in the same spiral.

Clifford Geertz, in his comparative essay on Balinese and Moroccan systems of irrigation, stated that "an established society is the end point of such a long history of adaptation that it has, as it were, made of that environment a dimension of itself" (Geertz 1972: 38). Geertz enlightened a relation between the environment and social life, or landscape and culture, by saying that the former is a kind of comment about the second, and vice versa. Adopting this point of view, leukemia is a cultural connector that stimulates the construction of its own horizon of meaning by underlining the relations between the disease and a numbers of factors attracting anxiety and social fears. The analytical frame that I have used here looks at the ensembles of entities working in the same social space, including viruses, politicians, criminals and what is traditionally labelled the "local community" (Ingold and Pàlsson 2013). A bottom-up representation of leukemia shapes a worldview through which people come to know their social environment: social dysfunctions constitute the grounds for a moral commentary about leukemia, and leukemia constitutes the grounds for a moral commentary about social dysfunctions. The members of the anti-leukemia association tried to shift from a private experience of mourning to a public engagement with environmental issues, a transition that is still in the making. By reading leukemia as environment-related rather than as a function of genetics, local activists constructed its representation as a social disease: leukemia is able to affect human bodies if humans are isolated entities whose poor cooperation makes them unable to control the ecosocial factors that allegedly underlie the disease.

\section{References}

Ariès, P. 1977. L'homme devant la mort. Paris: Éditions du Seuil (1991. The hour of our death. Oxford: Oxford University Press).

Auyero J. and D. Swistun. 2008. The social production of toxic uncertainty. American Sociological Review 73 (3): 357-379.

Belson, M., K. Beverely and A. Holmes. 2007. Risk factors for acute Leukemia in children: a review. Environmental Health Perspectives 115 (1): 138-145.

Comaroff, J. and Comaroff, J. (eds.) 1993. Modernity and its malcontents: ritual and power in postcolonial Africa. Chicago: University of Chicago Press.

Fischer, M.J. 2007. Four genealogies for a recombinant anthropology of science and technology. Cultural Anthropology 22 (4): 539-615.

Geertz, C. 1972. The wet and the dry: traditional irrigation in Bali and Morocco. Human Ecology 1(1): $23-39$.

Goodman, A. 2009. Framing health, risk, and adversity. In C. Panter-Brick and A. Fuentes (eds.), Health, risk and adversity. Oxford: Berghahn Books. Ppxiii-xvi.

Ingold, T. 2000. Globes and spheres: the topology of environmentalism. In T. Ingold (ed.) The perception of the environment: essays in livelihood, dwelling and skill. London: Routledge. Pp 209-218.

Kasim, K., P. Levallois, B. Abdous, P. Auger and K.C. Johnson. 2005. Lifestyle factors and the risk of adult Leukemia in Canada. Cancer Causes and Control 16 (5): 489-500.

Koensler A. and C. Papa 2013. Introduction: beyond anthropocentrism, changing practices and the politics of 'nature.' Journal of Political Ecology 20: 286-294.

Lansing, J.S. 2003. Complex adaptive systems. Annual Review of Anthropology 32: 183-204.

Latour, B. 2004. Politics of nature: how to bring the sciences into democracy. Cambridge: Harvard University Press (1999. Politiques de la nature. Comment faire entrer les sciences en démocratie. Paris: La Decouverte et Syros).

Latour, B. 2005. Reassembling the social: an introduction to actor-network theory. Oxford: Oxford University Press.

Pang, J. et al. 2002. Incidence of Leukemia in Asian migrants to the United States and their descendants. Cancer Causes and Control 13 (9): 791-795.

Phelan, J. B.G. Link, A. Diez-Roux, I. Kawachi and B. Levin. 2004. "Fundamental causes" of social inequalities in mortality: a test of the theory. Journal of Health and Social Behavior 45 (3): 265-285.

Richardson, D.B. 2008. Temporal variation in the association between Benzene and Leukemia mortality. Environmental Health Perspectives 116 (3): 370-374. 
Scélo, G. C. Metayer, L. Zhang, J.L. Wiemels, M.C. Aldrich, S. Selvin, S. Month, M.T. Smith and P.A. Buffler. 2009. Household exposure to paint and petroleum solvents, chromosomal translocations, and the risk of childhood Leukemia. Environmental Health Perspectives 117 (1): 133-139.

Schmitz-Feuerhake, I., B. Dannheim, A. Heimers, B. Oberheitmann, H. Schröder, and H. Ziggel. 1997. Leukemia in the proximity of a German boiling-water nuclear reactor: evidence of population exposure by chromosome studies and environmental radioactivity. Environmental Health Perspectives 105, Supplement 6: Radiation and Human Health: 1499-1504.

Shrader-Frechette, K. 2002. Environmental justice. Creating equality, reclaiming democracy. Oxford: Oxford University Press.

Thomas, L.V. 1975. Anthropologie de la mort. Paris: Suyot.

Van Ginkel, R. 1998. The repatriation of anthropology: some observations on endo-ethnography. Anthropology \& Medicine 5 (3): 251-267.

Ward, M.H., J.S. Colt,C. Metayer, R.B.Gunier, J.Lubin,V.Crouse, M.G. Nishioka, P. Reynolds and P.A. Buffler. 2009. Residential exposure to Polychlorinated Biphenyls and Organochlorine pesticides and risk of childhood Leukemia. Environmental Health Perspectives 117 (6): 1007-1013.

Wigle, D.T., M.C. Turner and D. Krewski. 2009. A systematic review and meta-analysis of childhood Leukemia and parental occupational pesticide exposure. Environmental Health Perspectives 117 (10): 1505-1513.

Zavestoski S., K, Agnello, F. Mignano and F. Darroch. 2004. Issue framing and citizen apathy toward local environmental contamination. Sociological Forum 19 (2): 255-283.

\begin{abstract}
From a political ecology perspective, anthropogenic threats to the environment can be understood in terms of a lack of power by local people. By analysing discourses about the spread of leukemia in rural Eastern Sicily, the connection between 'toxic environments' and 'damage to human health' is mediated by a concern about democracy, meaning a condition that is to be attained and refreshed continuously through the active participation of citizens. In this case study, I argue that leukemia becomes a socio-political disease that stems from political apathy.
\end{abstract}

Keywords: Leukemia, Sicily, environment, apathy, children

\title{
Résumé
}

Du point de vue de l'écologie politique, les menaces à l'environnement découlant de l'action humaine peuvent être comprise en termes de manque de responsabilisation des populations locales. En analysant les discours sur la diffusion de la leucémie dans les régions rurales de la Sicile orientale, on peut voir que le lien entre «environnement toxique» et «atteinte à la santé humaine" est médiée par un rapport avec la démocratie, considérée comme une condition qui doit être atteinte et toujours construite à travers la participation active des citoyens. Dans cette étude de cas, je montre que la leucémie est une maladie socio-politique qui résulte d'une apathie politique.

Mots-clés: leucémie, Sicile, environnement, apathie, enfants

\begin{abstract}
Da una prospettiva di ecologia politica, le minacce all' ambiente originate dall' azione umana possono essere comprese in termini di una mancanza di potere delle popolazioni locali. Analizzando i discorsi relativi alla diffusione della leucemia nella Sicilia rurale orientale, si può vedere che la connessione tra "ambienti tossici" e "danni alla salute umana" è mediata da una relazione circa la democrazia, considerata come una condizione che deve essere raggiunta e continuamente alimentata attraverso la partecipazione attiva dei cittadini. In questo caso di studio, mostro che la leucemia diventa una malattia sociopolitica che deriva da una apatia politica.
\end{abstract}

Parole chiave: leucemia, Sicilia, ambiente, apatia, bambini 